\title{
COVID-19, impact on myeloma patients
}

\section{Inès Dufour ${ }^{1}$. Juliette Raedemaeker ${ }^{1}$. Fabio Andreozzi ${ }^{1}$ - Géraldine Verstraete ${ }^{1}$ - Sarah Bailly ${ }^{1} \cdot$ Michel Delforge $^{2}$. Pauline Storms $^{1,2}$. Caroline Jacquy ${ }^{3} \cdot$ Ann Van de Velde $^{4} \cdot$ Philippe Mineur $^{5}$. Marie Lejeune ${ }^{6} \cdot$ Deborah Bauwens $^{7}$. Florence Van Obbergh ${ }^{1,8} \cdot$ Alain Kentos $^{8} \cdot$ Jasmine Nguyen $^{9} \cdot$ Karel Fostier $^{10} \cdot$ Anne De Weweire $^{11}$. Nathalie Meuleman ${ }^{12} \cdot$ Marie-Christiane Vekemans $^{1}$ (D)}

Received: 8 May 2020 / Accepted: 14 June 2020 / Published online: 23 June 2020

(C) Springer-Verlag GmbH Germany, part of Springer Nature 2020

To the Editor:

The worldwide COVID-19 pandemic is expected to be a devastating infection in patients with chronic hematological disorders. So far, no data have been reported in multiple myeloma (MM), a disease characterized by a severe humoral and cellular immune deficiency that exposes patients to infectious complications.

In order to assess the impact of COVID-19 in the Belgian MM community, we collected data on the disease by sending questionnaires to 30 different cancer centers. As of April 12, 2020, 20 symptomatic MM patients were confirmed with COVID-19 in 12 out of 20 hospitals that answered the survey (Table 1).

Median age was 68 years (range, 57-83). Twelve patients were male, 8 of African origin (5 North-Africans, 3 Blacks), 14 suffered from cardiovascular or renal comorbidities, 5 from

Inès Dufour and Juliette Raedemaeker contributed equally to this work.

Marie-Christiane Vekemans

Marie-christiane.vekemans@uclouvain.be

1 Department of Hematology, Cliniques universitaires Saint-Luc, UCL, 1200 Brussels, Belgium

2 University Hospital Leuven, Leuven, Belgium

3 Centre Hospitalier Ambroise Paré, Mons, Belgium

4 University Hospital Antwerpen, Antwerp, Belgium

5 Grand Hôpital de Charleroi, Charleroi, Belgium

6 Centre Hospitalier Universitaire de Liège, Liège, Belgium

7 Clinique Saint-Jean, Brussels, Belgium

8 Hôpital de Jolimont, Haine-Saint-Paul, Belgium

9 Centre Hospitalier Régional de Namur, Namur, Belgium

10 University Hospital Brussels, Brussels, Belgium

11 Centre Hospitalier EpiCURA, Mons, Belgium

12 Institut Jules Bordet, Brussels, Belgium diabetes, and 3 from another neoplasm. Sixteen were under therapy, mainly IMiD-based combinations $(n=13,81 \%)$. Previous ASCT was noted in 8 (median, 7 years), immunoparesis in 6.

The most common initial symptoms were fever $(n=13$, $65 \%)$, cough $(n=11,55 \%)$, dyspnea $(n=10,50 \%)$, and hypoxemia $(\mathrm{SaO} 2<93 \%)(n=9,45 \%)$. Diarrhea, skin, joint, or neurological complains were uncommon. Clinical status [1] was considered as mild in $5(25 \%)$, severe in $13(65 \%)$, or critical in $2(10 \%)$, with lung infiltrates reported on imaging in $16(80 \%)$ and multiple organ failure in $1(5 \%)$. Eleven patients presented a grade 4 eosinopenia (64\%). Grade 3-4 lymphopenia was common, mostly related to corticosteroids administration.

Hospitalization was required in 18 patients for a median of 12 days (range, 3-32), 5 in ICU with 2 needing mechanical ventilation. Most patients required $\mathrm{O} 2$ administration, in addition to antibiotics in 13 (65\%), and hydroxychloroquine in 14 (70\%), following the Belgian guidelines [2]. No patients received anti-IL6 or other antiviral therapy, since access was restricted to clinical trials. No thromboembolic complications were reported, but most patients were under prophylaxis.

Adverse outcome occurred in 7 patients (median age, 77; range, 58-83). All suffered from either a cardiovascular comorbidity or a secondary cancer, all were under dexamethasone (median monthly dose, $80 \mathrm{mg}$ ), and 5 had a progressive disease. In addition, 5 were of African origin. We failed to identify any impact of ISS stage, immunoparesis, and number of previous lines of therapy including ASCT. Time from MM diagnosis to COVID-19 was longer in this group, but not statistically significant. Of note, no post-mortem studies were performed.

Our limited experience of COVID-19 emphasizes the severity of this condition in MM patients, with a high mortality incidence (35\%). However, based on these preliminary data, in a country where 800 new MM are diagnosed each year and where 52,000 cases of COVID-19 have been reported so far, 
Table 1 Clinical features and outcomes in multiple myeloma patients

\begin{tabular}{|c|c|c|c|}
\hline & Total $(n=20)$ & Survivors $(n=13)$ & Deceased $(n=7)$ \\
\hline Median age, year (range) & $68(58-83)$ & $64(57-81)$ & $77(58-83)$ \\
\hline Male sex, $n(\%)$ & $12(60)$ & $8(61)$ & $4(57)$ \\
\hline \multicolumn{4}{|l|}{ Ethnicity, $n(\%)$} \\
\hline Caucasian & $11(55)$ & $9(69)$ & $2(28)$ \\
\hline African (North-Africans/Blacks) & $5(25) / 3(15)$ & $1(7) / 2(15)$ & $4(57) / 1(14)$ \\
\hline Hispanic & $1(5)$ & $1(7)$ & 0 \\
\hline \multicolumn{4}{|l|}{ Comorbidities, $n(\%)$} \\
\hline Cardiovascular and/or renal disease & $14(70)$ & $9(69)$ & $5(71)$ \\
\hline Diabetes mellitus & $5(25)$ & $2(15)$ & $3(42)$ \\
\hline Other cancer & $3(15)$ & 0 & $3(42)$ \\
\hline Hypogammaglobulinemia & $6(30)$ & $4(30)$ & $2(28)$ \\
\hline \multicolumn{4}{|l|}{ MM characteristics } \\
\hline Mean time from MM diagnosis to COVID-19, months & 65 & 57 & 79 \\
\hline Salmon Durie Ib/ II-III, $n / n$ & $1 / 19$ & $1 / 12$ & $0 / 7$ \\
\hline ISS stage II-III, $n /$ total $n(\%)$ & $8 / 16(50)$ & $6 / 11(54)$ & $2 / 5(40)$ \\
\hline Progressive disease at COVID-19 diagnosis, $n(\%)$ & $8(40)$ & $3(23)$ & $5(71)$ \\
\hline Therapy at time of COVID- $19, n(\%)$ & $16(80)$ & $11(85)$ & $5(71)$ \\
\hline 1st line-bortezomib/lenalidomide based & $6(30)$ & $5(38)$ & $1(14)$ \\
\hline- no treatment & $3(15)$ & $1(7)$ & $2(28)$ \\
\hline $2 \mathrm{~d}$ line-daratumumab- $\mathrm{Rd}$ & $3(15)$ & $3(23)$ & 0 \\
\hline- no treatment & $1(5)$ & $1(7)$ & 0 \\
\hline$\geq 3 \mathrm{~d}$ line-pomalidomide/daratumumab based & $8(40)$ & $4(30)$ & $4(56)$ \\
\hline Previous ASCT & $8(40)$ & $6(46)$ & $2(28)$ \\
\hline \multicolumn{4}{|l|}{ Signs and symptoms, $n(\%)$} \\
\hline Fever & $13(65)$ & $9(69)$ & $4(57)$ \\
\hline Cough & $11(55)$ & $8(61)$ & $3(42)$ \\
\hline Dyspnea & $10(50)$ & $8(51)$ & $2(28)$ \\
\hline Hypoxemia $(\mathrm{SaO} 2<93 \%)$ & $9(45)$ & $6(46)$ & $3(42)$ \\
\hline Confusion & $4(20)$ & $2(15)$ & $2(28)$ \\
\hline Diarrhea & $2(10)$ & 0 & $2(28)$ \\
\hline Multiple organ failure & $1(5)$ & 0 & $1(14)$ \\
\hline \multicolumn{4}{|l|}{ Clinical status, $n(\%)$} \\
\hline Mild & $5(25)$ & $4(31)$ & $1(14)$ \\
\hline Severe & $13(65)$ & $9(69)$ & $4(57)$ \\
\hline Critical & $2(10)$ & 0 & $2(28)$ \\
\hline \multicolumn{4}{|l|}{ Laboratory values } \\
\hline Lymphopenia $<1000 / \mathrm{mm}^{3}, n /$ total $n(\%)$ & 16/17 (94) & $10 / 10(100)$ & 6/7 (86) \\
\hline Eosinopenia $<50 / \mathrm{mm}^{3}, n /$ total $n(\%)$ & $11 / 17(64)$ & $5 / 10(50)$ & $6 / 7(86)$ \\
\hline Thrombocytopenia $<150,000 / \mathrm{mm}^{3}, n /$ total $n(\%)$ & $9 / 17(53)$ & $4 / 10(40)$ & $5 / 7(71)$ \\
\hline \multicolumn{4}{|l|}{ Radiological characteristics, $n(\%)$} \\
\hline Lung infiltrates on chest $\mathrm{x}$-rays or $\mathrm{CT}$ & $16(80)$ & $11(85)$ & $5(71)$ \\
\hline Hospitalization, $n(\%)$ & $18(90)$ & $11(85)$ & $7(100)$ \\
\hline Median duration, days (range) & $12(3-32)$ & $15(6-32)$ & $9(3-13)$ \\
\hline ICU admission, $n(\%)$ & $5(25)$ & $2(15)$ & $3(42)$ \\
\hline Median duration, days (range) & $6(3-10)$ & $5.5(4-7)$ & $6(3-10)$ \\
\hline \multicolumn{4}{|l|}{ Management, $n(\%)$} \\
\hline Oxygenotherapy & $15(75)$ & $9(69)$ & $6(86)$ \\
\hline Mechanical ventilation & $2(10)$ & 0 & $2(28)$ \\
\hline Hydroxycholoroquine & $14(70)$ & $9(69)$ & $5(71)$ \\
\hline Antibiotics & $13(65)$ & $9(69)$ & $4(57)$ \\
\hline Anti-IL6, others & 0 & 0 & 0 \\
\hline
\end{tabular}

ASCT autologous stem cell transplant, ICU intensive care unit, ISS International Staging System, $M M$ multiple myeloma, $n$ number, $R d$, lenalidomidedexamethasone 
this complication remains very rare. Age, comorbidities, disease status, and ethnicity may be relevant. Ethnic differences in angiotensin-converting-enzyme-2 expression might play a role, as well as socioeconomic, cultural, or other genetic predisposing factors [3]. Our data support also the need to reduce at least the dexamethasone dosage, as proposed by others [4, 5]. Grade 4 eosinopenia is common [6], a possible landmark feature of COVID-19. Further investigations are mandatory in order to assess the impact of this new viral infection on MM patients.

Authors' contributions ID, JR, FA, GV, and MCV analyzed the data. ID, JR, and MCV wrote the manuscript.

All authors collected the data and approved the final manuscript.

Availability of data and material Yes.

\section{Compliance with ethical standards}

Conflict of interest The authors declare no conflict of interest.

Ethics approval Yes.

Consent to participate Yes.

Consent for publication Yes.

Code availability Not applicable.

\section{References}

1. Wu J, McGoogan JM (2020) Characteristics of and important lessons from the coronavirus disease 2019 (COVID-19) outbreak in China: summary of a report of 72314 cases from the Chinese Center for Disease Control and Prevention. JAMA 323:1239. https://doi.org/ 10.1001/jama.2020.2648

2. Van Ierssel S, Dauby N, Bottieau E, Huits R (2020) Interim clinical guidance for adults with suspected or confirmed covid-19 in Belgium. Sciensano; https://covid-19.sciensano.be/sites/default/ files/Covid19/COVID-19_InterimGuidelines_Treatment_ENG.pdf. Accessed 07 Apr 2020

3. Kamlesh K, Awadhesh Kumar S, Manish P, Wasim H (2020) Is ethnicity linked to incidence or outcomes of Covid-19? Br Med J 369:1548

4. Malard F, Mohty M (2020) Management of patients with multiple myeloma during the COVID-19 pandemic. Lancet Haematol. https:// doi.org/10.1016/S2352-3026(20)30124-1

5. Rajkumar SV, Cavo M, Mikhail J, Mateos MV, Jackson G, Moreau P, Richardson P, Dhakal B (2020) COVID-19 and multiple myeloma: frequently asked questions, version 1.1, last updated April 23, 2020. American Society of Hematology, Covid-19 resources. https:// www.hematology.org/covid-19/covid-19-and-multiple-myeloma. Accessed 23 Apr 2020

6. Zhang JJ, Dong X, Cao YY, Yuan YD, Yang YB, Yan YQ, Akdis CA, Gao YD (2020) Clinical characteristics of 140 patients infected with SARS-CoV-2 in Wuhan, China. Allergy. https://doi.org/10. 1111/all.14238.v

Publisher's note Springer Nature remains neutral with regard to jurisdictional claims in published maps and institutional affiliations. 